\title{
Penyuluhan Peran LPMK Dalam Membangun Sumber Daya Manusia Kelurahan Sukorame Kota Kediri
}

\author{
Ahmad Idris ${ }^{1}$, Suseno Hendratmoko ${ }^{2}$, dan Heru Sutapa ${ }^{3}$ \\ Program Studi Manajemen Fakultas Ekonomi Universitas Islam Kadiri ${ }^{1,2,3}$ \\ ahmadidris@uniska-kediri.ac.id ${ }^{1}$, susenohendratmoko@uniska-kediri.ac.id ${ }^{2}$,dan herusutapa@uniska-kediri.ac.id ${ }^{3}$
}

\begin{abstract}
Community service is counseling on the role of Village Community Empowerment Institute in building human resources. The Kediri city government, especially the Sukorame village, must have more commitment in strengthening community capacity and independence, through empowering community institutions as Sukorame village partners in the task and function of community empowerment, building a socio-economic base at the local level and being able to mobilize community participation in development. With participation and mutual cooperation in development, it is largely determined by the function and role of the partnership of the village community institutions. The current weakening of participation, role and function of community institutions in the village, has resulted in clogged channels of community aspirations, social, cultural conflicts and waning customs values. In the future a program / activity is needed that is able to stimulate / strengthen community independence in the village. It is hoped that the form of structuring and empowerment of community institutions can restore the situation synergistically with the relationship between the village government and the community in government services, implementation of development and community empowerment.
\end{abstract}

Keywords: counseling, community, development.

\begin{abstract}
Abstrak
Pengabdian kepada masyarakat yaitu penyuluhan peran Lembaga Pemberdayaan Masyarakat Kelurahan dalam membangun sumber daya manusia. Pemerintah kota Kediri khususnya kelurahan Sukorame harus memiliki komitmen lebih dalam penguatan kapasitas dan kemandirian masyarakat, melalui pemberdayaan lembaga kemasyarakatan sebagai mitra kelurahan Sukorame dalam tugas dan fungsi pemberdayaan masyarakat, membangun basis sosial ekonomi di tingkat lokal dan mampu menggerakkan partisipasi masyarakat dalam pembangunan. Dengan partisipasi dan kegotongroyongan dalam pembangunan sangat ditentukan oleh fungsi dan peran kemitraan lembaga kemasyarakatan kelurahan. Melemahnya partisipasi, peran serta fungsi lembaga kemasyarakatan di kelurahan saat ini, berakibat tersumbatnya saluran aspirasi masyarakat, terjadinya konflik sosial, budaya maupun memudarnya nilai adat-istiadat, kedepan diperlukan program/kegiatan yang mampu mendorong/menstimulasi untuk menguatkan kembali kemandirian masyarakat di kelurahan. Bentuk kegiatan penataan dan pemberdayaan lembaga kemasyarakatan diharapkan dapat memulihkan situasi sinergis hubungan pemerintah kelurahan dengan masyarakat dalam pelayanan pemerintahan, pelaksanaan pembangunan maupun pemberdayaan masyarakat.
\end{abstract}

Kata Kunci: penyuluhan, masyarakat, pembangunan. 


\section{Pendahuluan}

\section{UU No 6 tahun 2014 pada Bab XII}

Pasal 94, disebutkan bahwa: 1.Desa mendayagunakan lembaga kemasyarakatan Desa yang ada dalam membantu pelaksanaan fungsi penyelenggaraan Pemerintah Desa, pelaksanaan pembangunan Desa, pembinaan kemasyarakatan Desa, dan pemberdayaan masyarakat Desa; 2.Lembaga kemasyarakatan Desa sebagaimana dimaksud pada ayat 1 merupakan wadah partisipasi masyarakat Desa sebagai mitra Pemerintah Desa; 3.Lembaga kemasyarakatan Desa, ikut serta merencanakan dan melaksanakan pem-bangunan, serta meningkatkan pelayanan masyarakat Desa; 4.Pelaksanaan program dan kegiatan yang bersumber dari Peme-rintah, Pemerintah Daerah Provinsi, Peme-rintah Daerah Kabupaten/Kota, dan lembaga non-Pemerintah wajib memberdayakan dan mendayagunakan lembaga kemasyarakatan yang sudah ada di Desa.

UU No 23 tahun 2014 tentang Pemerintah Daerah, khususnya Pasal 229 menjelaskan tugas Lurah danam membantu Camat selain tugas pemerintahan dan pelayanan, melakukan pemberdayaan masya-rakat. Dalam Peraturan Pemerintah No 73 tahun 2005 disebutkan bahwa Lembaga Kemasyarakatan Kelurahan adalah lembaga yang dibentuk oleh masyarakat sesuai dengan kebutuhan dan merupakan mitra lurah dalam memberdayakan masyarakat, yang memiliki tugas membantu lurah dalam melaksanakan urusan pemerintahan, pembangunan, sosial kemasyarakatan dan pemberdayaan masya-rakat. Fungsi lembaga kemasyarakatan kelurahan antara lain: (i)penampungan dan penyaluran aspirasi masyarakat, (ii)penana-man dan pemupukan rasa persatuan dan kesatuan masyarakat dalam kerangka memperkokoh Negara Kesatuan Republik Indonesia, (iii)Peningkatan kualitas dan percepatan pelayanan pemerintahan pada masyarakat, (iv)Penyusunan rencana, pelak-sana dan pengelola pembangunan secara partisipatif, (v)Penggerak prakarsa swadaya gotongroyong masyarakat, (vi)Pendayagu-naan dan pengembangan potensi sumber daya serta keserasian lingkungan hidup, (vii)Pengembangan kreatifitas, pencegahan kenakalan, penyalahgunaan obat terlarang di remaja, (viii)Pemberdayaan dan peningkatan kesejahteraan keluarga, (ix)Pemberdayaan dan perlindungan hak politik masyarakat, (x)Pendukung komunikasi informasi, sosia-lisasi antar pemerintah dan masyarakat.

Pemerintah kota Kediri dalam hal ini kelurahan Sukorame harus memiliki komit-men lebih dalam penguatan kapasitas dan kemandirian kelurahan, melalui pember-dayaan lembaga kemasyarakatan sebagai mitra kelurahan Sukorame dalam tugas dan fungsi pemberdayaan masyarakat, dapat membangun basis sosial ekonomi di tingkat lokal dan dapat menggerakkan partisipasi masyarakat dalam membantu kelancaran pembangunan. Berkembangnya partisipasi dan kegotongroyongan dalam pembangunan sangat ditentukan oleh fungsi dan peran kemitraan lembaga kemasyarakatan yang ada di kelurahan.

Melemahnya peran dan fungsi Lembaga kemasyarakatan pada saat ini, berakibat tersumbatnya saluran aspirasi masyarakat, terjadinya konflik sosial, budaya maupun memudarnya adat-istiadat yang ada, kedepan diperlukan program atau kegiatan yang mampu mendorong atau menstimulasi untuk menguatkan kembali kemandirian masyarakat kelurahan. Bentuk kegiatan penataan dan pemberdayaan lembaga kemasyarakatan diharapkan agar dapat memulihkan situasi sinergis hubungan pemerintah kelurahan dengan masyarakat dalam pelayanan pemerintahan, membantu pelaksanaan dan kelancaran dalam program pembangunan 
maupun kegiatan pember-dayaan masyarakat.

\section{Pelaksanaan Dan Metode}

Penyuluhan yang dilakukan bertujuan untuk: 1.mengidentifikasi permasalahan yang sedang dihadapi oleh anggota LPMK (Lembaga Pemberdayaan Masyarakat Kelurahan); 2.membantu anggota dalam menyelesaikan permasalahan yang dihadapi melalui kegiatan penyuluhan; dan 3.membantu meningkatkan partisipasi anggota LPMK. Kegiatan penyuluhan dilaksanakan pada hari Sabtu tanggal 10 September 2016 dilaksanakan di salah satu rumah anggota

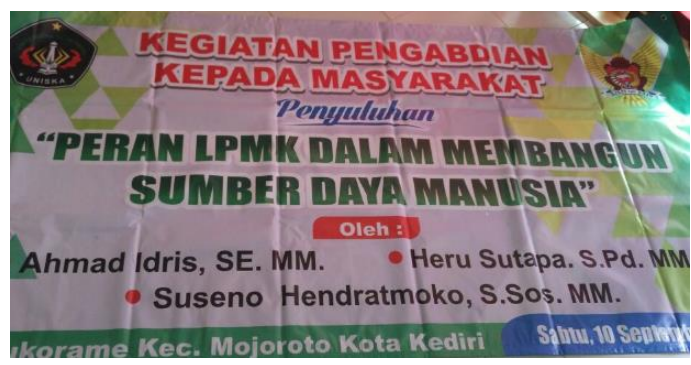

Gambar 1. Spanduk kegiatan penyuluhan

LPMK kelurahan Sukorame.

Berdasarkan hasil musyawarah yang dilakukan perwakilan masyarakat di kelurahan Sukorame dalam pembentukan kepengurusan LPMK dan telah disahkan melalui Keputusan Kepala Kelurahan Sukorame Kecamatan Mojoroto Kota Kediri No 15 Tahun 2016 tanggal 2 Maret 2016 tentang Pengesahan Kepengurusan Lembaga Pemberdayaan Masyarakat Kelurahan (LPMK) masa bhakti 2016-2019 Kelurahan Sukorame.

Adapun susunan kepengurusan LPMK terdiri dari Ketua, Sekretaris, Bendahara, Sie Agama, Sie Keamanan Ketentraman ketertiban, Sie Pendidikan Penerangan, Sie Pembangunan, Sie Perekonomian Koperasi, Sie Kesehatan, Sie Kependudukan Kesejahteraan Sosial,
Sie Pemberdayaan Perempuan Keluarga Berencana, Sie Lingkungan Hidup, dan Sie Pemuda Olahraga Kesenian.

\section{Hasil dan Pembahasan}

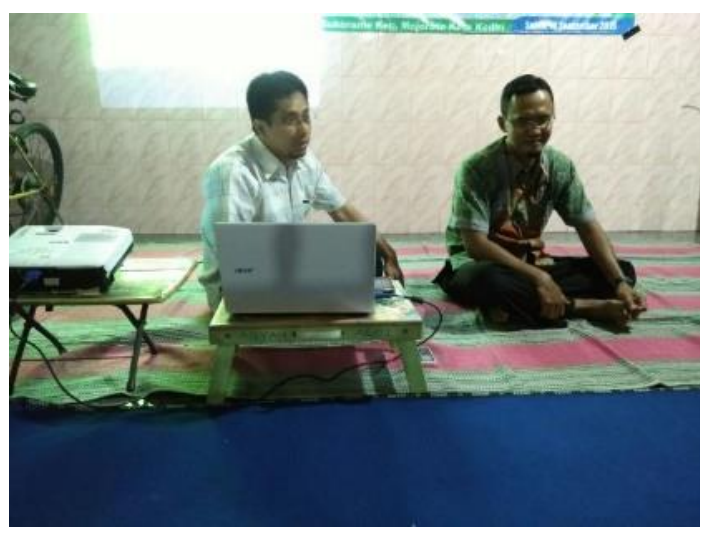

Gambar 2. Penyampaian materi

$\begin{array}{llr}\text { LPMK } & \text { mempunyai tugas } \\ \text { membantu kelurahan di bidang }\end{array}$ pembangunan, dan pem-berdayaan masyarakat, meliputi : menyusun rencana pembangunan secara parisipatif seperti musyawarah perencanaan pemba-ngunan (musrenbang), menggerakkan swa-daya gotong royong masyarakat, melak-sanakan dan mengendalikan pembangunan partisipatif.

Dalam melaksanakan tugasnya, LPMK mempunyai fungsi: 1.penampungan dan penyaluran aspirasi masyarakat dalam pembangunan; 2.penanaman dan pemupukan rasa persatuan dan kesatuan masyarakat dalam kerangka memperkokoh Negara Kesatuan Republik Indonesia; 3.peningkatan kualitas dan percepatan pelayanan dari pemerintah kepada masyarakat; 4.Penyusu-nan rencana, pelaksanaan, pelestarian dan pengembangan hasil-hasil pembangunan secara partisipatif; 5.Penumbuhkembangkan dan penggerak prakarsa, partisipasi, serta swadaya gotong royong masyarakat; dan 6.Penggali, pendayagunaan dan pengem-bangan 
potensi sumber daya alam serta keserasian lingkungan hidup.

$$
\text { Pemberdayaan masyarakat }
$$

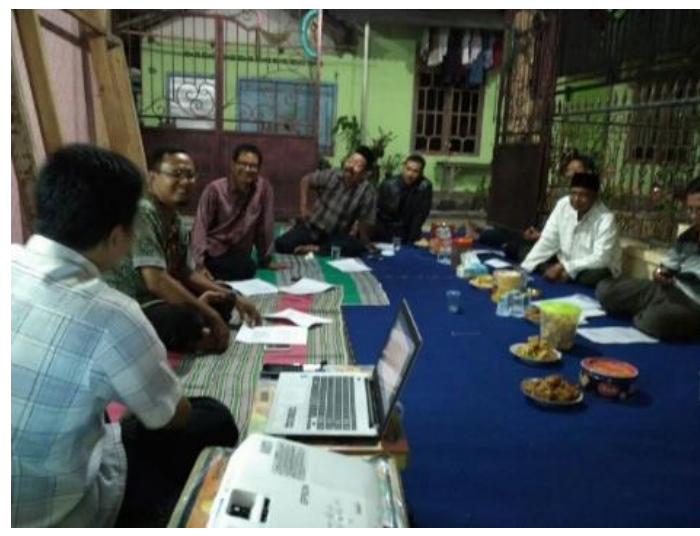

Gambar 3. Suasana rileks saat penvuluhan

kelurahan dilakukan dengan : 1.mendorong partisipasi masyarakat dalam perencanaan dan pem-bangunan kelurahan yang dilaksanakan secara swakelola oleh pihak kelurahan; 2.mengembangkan program dan kegiatan pembangunan dari kelurahan secara berkelanjutan dengan mendayagunakan sumber daya manusia dan sumber daya alam yang ada di Kelurahan; 3.menyusun perencanaan pembangunan kelurahan sesuai dengan prioritas, potensi, dan nilai kearifan lokal; 4.menyusun perencanaan dan penganggaran yang berpihak kepada kepentingan warga miskin, warga disabilitas, perempuan, anak, dan kelompok marginal; 5.mengembangkan sistem transparansi dan akuntabilitas dalam penyelenggaraan peme-rintahan kelurahan dan pembangunan kelurahan; 6.mendayagunakan lembaga kemasyarakatan kelurahan dan lembaga adat; 7.mendorong partisipasi masyarakat dalam penyusunan kebijakan kelurahan yang dilakukan melalui musyawarah kelurahan.

Kepercayaan dan reputasi menjadi hal penting yang harus dimiliki setiap lembaga kemasyarakatan didalam menjalankan tugasnya. Lembaga kemasyarakatan selalu melekat dalam kehidupan masyarakat, tidak dipersoalkan apakah bentuk masyarakat itu masih sederhana ataupun masyarakat maju. Setiap masyarakat sudah tentu tidak akan terlepas dengan semakin banyak dan kompleks kebutuhan atau kepentingan pokok/utama yang apabila dikelompok-kelompokkan terhimpun menjadi lembaga kemasyarakatan.

Dalam sebuah organisasi, pengelolaan reputasi merupakan tanggung jawab bersama dan oleh masing-masing pihak, tidak hanya sadar dan terpercaya terhadap proses pengelolaan reputasi saja akan tetapi adanya komitmen serta konsisten guna mewujudkannya.

Reputasi lembaga kemasyarakatan merupakan resultan dari pemenuhan terhadap ekspektasi rasional dan ekspektasi emosional masing-masing stakeholder terhadap lem-baga kemasyarakatan dalam setiap momen interaksinya. Ekspektasi rasional lebih didasarkan atas kinerja atau kualitas dari produk yang dikonsumsi sedangkan ekspektasi emosional lebih didasarkan atas perilaku dan persepsi stakeholder.

Pendanaan LPMK bersumber dari : 1.Pemerintah Pusat/Daerah bisa berupa fisik maupun non fisik untuk mewujudkan berjalannya kegiatan LPMK Sukorame; 2.Swadaya masyarakat sendiri tanpa adanya dorongan dari pihak luar murni dana diperoleh dari masyarakat untuk mewujudkan berja-lannya kegiatan dari LPMK Sukorame; 3.Bantuan lain yang sah dan tidak mengikat. Pendanaan bisa juga dari pihak luar/lain kepada LPMK Sukorame dengan syarat bantuan tersebut tidak mengikat dan perjanjian kedua belah pihak. Bantuan tersebut semata-mata untuk kegiatan LPMK atau kegiatan masyarakat lainnya.

Kemitraan menurut Kamus Besar Bahasa Indonesia adalah perihal hubungan (jalinan kerjasama) sebagai mitra (Tim Penyusun, 1996). Peran LPMK kelurahan 
Sukorame dalam menumbuhkembangkan, penggerak prakarsa dan partisipasi, serta swadaya gotong royong masyarakat di kelurahan Sukorame dengan turut melibatkan masyarakat dalam kegiatan yang diperun-tukkan bagi masyarakat itu sendiri. Dapat dilihat kegiatan yang dilakukan LPMK tidak begitu banyak, kegiatan lebih didominasi pada kegiatan gotong royong dan kegiatan keamanan. Dalam melaksanakan kegiatan LPMK dapat bekerjasama dengan pemerintah ataupun lembaga kemasya-rakatan yang ada di kelurahan Sukorame.

LPMK berhak menerima bimbingan, pelatihan, pembinaan dari Pemerintah Daerah. Pemerintah Daerah melakukan fungsi bimbingan, pelatihan, pembinaan, dan pengawasan terhadap LPMK yang pelaksanaannya dapat dilimpahkan kepada Camat setempat. Peran LPMK dalam mendukung perencanaan pembangunan yaitu mengajak para ketua RT maupun RW dalam menyusun usulan kegiatan pembangunan. LPMK sebagai mediator menpunyai tugas mensosialisasikan hasil-hasil usulan rencana pembangunan yang sudah ditetapkan dan dijadikan RPJM dan RPKT kelurahan kepada semua elemen masyarakat. LPMK sebagai motivator dituntut mampu memberikan pengarahan serta menggerakkan masyarakat di masingmasing wilayah RT/RW untuk selalu tampil dan berperan aktif baik dalam proses perencanaan pembangunan.

\section{Kesimpulan}

LPMK kelurahan Sukorame menjalankan tugas dan fungsinya belum maksimal dalam menampung dan menyalurkan aspirasi masyarakat yang ada di kelurahan Sukorame. LPMK kelurahan Sukorame memberikan peluang yang sama kepada masyarakat untuk menyampaikan aspirasi/usulan ataupun konsultasi terkait dengan permasalahan yang terjadi di masyarakat, yakni dalam hal pembangunan ataupun pemberdayaan masyarakat. Walaupun tidak semua aspirasi yang masuk bisa langsung ditanggapi karena kendala yang dihadapi, namun aspirasi masyarakat tersebut akan dipilih mana yang menjadi prioritas dan bisa langsung ditanggapi LPMK ataupun yang harus diserahkan kepada pemerintah Kelurahan.

\section{Saran}

Perlunya adanya media komunikasi informasi, sosialisasi antara pemerintah dan masyarakat agar pembangunan yang ada di kelurahan Sukorame harus dibenahi sehingga memberikan hasil yang memuaskan bagi masyarakat serta pemerintah kelurahan Sukorame.

\section{Daftar Pustaka}

Arbain, M. Wahyu. (2014). Peran Lembaga Pemberdayaan Masyarakat Kelurahan (LPMK) Dalam Pemberdayaan Masyarakat Di Kelurahan Muara Jawa Tengah Kecamatan Muara Jawa Kabupaten Kutai Kertanegara. Jurnal Ilmu Pemerintahan, 2 (4), 3259-3272.

Penyusun kamus Pusat Pembinaan dan Pengembangan Bahasa

Rafsanzani, H. Bambang, S. \& Suwondo. (2013). Kemitraan Lembaga Pemberdayaan Masyarakat Desa Dengan Kepala Desa Dalam Perencanaan Pembangunan Desa (Studi Kasus di Desa Sumber Ngepoh Kecamatan Lawang Kabupaten Malang). Jurnal Administrasi Publik, 1(4), 67-72. 